\title{
CORPORATE STRUCTURE ANALYSIS OF ORGANIZATIONS FROM NETWORK PERSPECTIVE
}

\author{
DOI: 10.17261/Pressacademia.2018.947 \\ RJBM- V.5-ISS.3-2018(6)-p.231-237
}

\section{Cigdem Baskici' ${ }^{1}$, Yavuz Ercil ${ }^{2}$}

${ }^{1}$ Başkent University, Baglica Campus 06790 Etimesgut, Ankara, Turkey. cbaskici@baskent.edu.tr, ORCID: 0000-0003-0712-1481

${ }^{2}$ Başkent University, Baglica Campus 06790 Etimesgut, Ankara, Turkey. yercil@baskent.edu.tr, ORCID: 0000-0003-2016-7329

To cite this document

Baskici, C., Ercil, Y. (2018). Corporate structure analysis of organizations from network perspective. Research Journal of Business and Management (RJBM), V.5(3), p.231-237.

Permanent link to this document: $\underline{\text { http://doi.org/10.17261/Pressacademia.2018.947 }}$

Copyright: Published by PressAcademia and limited licenced re-use rights only.

\section{ABSTRACT}

Purpose- The aim of our study is to reveal the corporate structure of organizations from network perspective. It is aimed to establish decision criteria for the efficiency and priority of actions in line with analysis results.

Methodology- We use the document relationships between all units of a professional organization with public institution status in 2016. The relations between these units are evaluated by network analysis. Six indicators such as integration, driving, driven, stability, criticality and precarious are used to describe the dynamic character of the organizational structure.

Findings- According to the analysis results, two units are defined as integrative, two are as driving and three of them as driven, two are critical and two of them are precarious. Overall system stability is $\% 56$. This means that the system in focus is not under the threat of neither disorganization nor inertia.

Conclusion- With study findings, it is possible to follow the dynamic reflection of any topic on the system and apply the targets of the units in the most appropriate way to the institutional structure.

Keywords: Network analysis, corporate structure, dynamic structure, strategic decision, strategic management.

JEL Codes: L14, M10, M19

\section{ÖRGÜTLERIN AĞ PERSPEKTiFINDEN KURUMSAL YAPI ANALIZi}

\section{ÖZET}

Amaç- Çalışmamızın amacı örgütlerin kurumsal yapısının ağ perspektifinden ortaya çıkarılmasıdır. Analiz sonuçları doğrultusunda eylemlerin etkinlik ve önceliği konusunda karar kriterlerinin oluşturulması amaçlanmaktadır.

Yöntem- Çalışmamızda kamu kurumu niteliğindeki bir meslek örgütünün tüm birimleri arasındaki 2016 yılı evrak ilişkileri dikkate alınmıştır. Birimler arasındaki bu ilişkiler ağ analizi ile değerlendirilmiştir. Örgütsel yapının dinamik karakterini tanımlamak için bütünleşme, harekete geçiricilik, harekete geçicilik, istikrar, kritiklik ve öngörülme olmak üzere altı gösterge kullanılmıştır.

Bulgular- Analiz sonuçlarına göre iki birim bütünleştirici, iki birim harekete geçirici, üç birim harekete geçici, iki birim kritik ve iki birim öngörülebilir olarak tanımlanmıştır. Bütün sistemin istikrarı ise \%56 olarak hesaplanmıştır. Bu durum, sistemin ne çözülme ne de atalet tehlikesi altında olduğunu göstermektedir.

Sonuç- Çalışma bulguları ile herhangi bir konunun sistem üzerindeki dinamik yansımasının takip edilmesi ve birim amaçlarının kurumsal yapıya en uygun şekilde uygulanabilmesi mümkün olabilmektedir.

Anahtar Kelimeler: Ağ analizi, kurumsal yapı, dinamik yapı, stratejik karar, stratejik yönetim.

JEL Kodları: L14, M10, M19 


\section{GiRiş}

Örgüt tarihi için ilk örneklerden biri olan Daniel McCallum'un 1854 yılındaki örgüt şeması kritik bilgileri verimli bir şekilde sunmak ve görevleri doğru kişiye devretmek için oluşturulmuştu (Rosenthal, 2013). O günden bugüne örgüt tasarımı evrimi içinde iş birliği ve uzmanlaşmayı takip etmek, yetki ve otoriteyi görmek, bölümlendirmeleri sağlamak, emir komuta zincirini oluşturmak, kontrol alanını belirlemek, merkezileşme-ademi merkezileşme seviyesini tanımlamak, formalleşmeyi sağlamak veya karmaşıkıkla baş etmek için pek çok tasarım geliştirildi. Bu açıdan bakıldığında yazında yaygın karşılaşılan biçimsel tanımlamalar içinde örgütsel tasarımın pek çok kavram açısından farklı yöntemlerle geliştirildiğini görmek mümkündür.

Çalışmamız örgütleri davranışın temeli olan ilişki açısından ele almaktadır. Bu açıdan bakıldığında örgüt tasarımı 3 temel kavram (iş birliği, otonomi, kontrol) altında gruplandırılabilmektedir (Ercil, 2014). Illk kez Margaret Wheatley (2006) doğanın bir ilişkiler yumağı olduğu, sosyal örgütlenmelerin de aslında bunun parçası olduğu konusundaki önermesini ortaya atmıştır. Bu önerme giderek daha somut uygulamalarla test edilmeye başlanmıştır. Bu çalışma bu çabalardan biridir ve ağ perspektifinden örgüt yapısını tanımlamayı hedeflemektedir.

Örgüt yapılarını ilişki temelli bir anlayışla tasarlayabilmek için yapılacak deneysel bir çalışma her şeyden önce şüphesiz kuramsal bir hazır oluşluk gerektirir. Bu çalışmanın kuramsal temeli; sistem bilimi, sosyo-teknik sistemler ve etki odaklı ağ yaklaşımı ile tesis edilmiştir. Çalışmamızda sistem bilimi sayesinde örgütleri oluşturan birimlerin birbirleri ile simbiyotik ilişkilerini anlama imkânımız oldu (Stacey, 1995; Bar-Yam, 1997; McKelvey, 1999). Sosyo-teknik sistem yaklaşımı sayesinde çalışmamızdaki ilişkilerin yapılarını bilişim altyapısı ile tanımlayabildik (Rousseau, 1977; Read vd., 2015; Hanseth ve Lyytinen, 2016). Bunların yanında etki odaklı ağ yaklaşımı ile birimlerin birbirleri arasındaki etkileşimi doğrusal olmayan bir anlayışla izleme olană̆ı yarattık (Linss ve Fried, 2010). Böylece bir sistem içinde birimler arasındaki etkileşimin sistemin geneli ve birbirleri arasındaki yapıyı nasıl değiştirebildikleri konusunda dinamik bir izleme yapmak mümkün oldu. Diğer bir ifade ile örgüt tasarımı açasından gelinen bugünkü noktayı biraz daha ileriye taşıyarak somut kavramlarla ilişkilere dayalı dinamik bir örgüt tasarımı tanımlamış olduk.

Etki odaklı ağ kuramı kavramları ile örgütsel tasarım çalışması birimlerin örgüt içinde dağıımları, pozisyonları ve birbirleri ile olan sistematik ilişkilerini yansıtmayı (James ve Jones, 1976) ve bu birimlerin istikrarlı temalar veya stratejiler etrafında organize olarak birbirlerine etkilerini (Lei ve Slocum, 2005) tanımlamayı gerektirir. Bu açıdan örgütsel yapıyı tanımlamak bir örgütteki birimlerin formal davranışlarını ilişkiye dayalı olarak ortaya çıkarmayı sağlayacak temel göstergeleri gerektirmektedir. Çalışmamızda bu davranışları tanımlayabilmek için kaynağını sistem biliminden alan ve ağ perspektifinde yer alan çeşitli göstergeler kullanılmıştır. Bunlar aynı zamanda birimlerin birbirlerinden nasıl etkileneceğine yönelik bir öngörüyü de yaratmaktadır. Bu durum bir bütün olarak birim davranışları ile kurumsal hedefler/stratejiler arasındaki potansiyel etkileşimin ortaya çıkarılmasını da mümkün kılacaktır. Ayrıca birimlerin eylemlerinin etkinlik ve önceliği konusunda karar kriterleri de oluşturulabilecektir.

Makale modelin kuramsal arka planının ele alınması ile başlamaktadır. İzleyen kısımda verilerin elde edilmesine ve kullanılan yönteme ilişkin bilgiler yer almaktadır. Bulgular kısmında çalışmanın analiz sonuçları sunulmuştur. Son bölümde ulaşılan sonuçlara, çalışmanın kısıtlııılarına ve gelecek çalışmalarla ilgili çeşitli önerilere yer verilmektedir.

\section{YAZIN INCELEMESI}

\subsection{Ağ Perspektifi ile Sistem Bilim Açısından Etkileşime ilişkin Temel Kavramlar}

Burt (1995)'e göre örgütler açısından ana hedef olan sermaye para, kişisel özellikler ve ilişkiler şeklinde üç çeşittir. Para ve kişisel özellikler bireyseldir. Ancak ilişkiler sosyal bir tanımdır ve o sosyal yapıya üye olan herkese aittir. Bu nedenle yararlı ilişkiler üzerine kurulu bir ağ yönetsel tanımlama itibariyle bir örgütlenme şeklidir. İlişkilere dayalı bir ağ kurabilmek için öncelikle gereksiz olmayan (nonredundant) bağlantıların kullanılması sonra da bu bağlantılardan bilgi akışının yönetilebilmesi gerekir (Burt, 1995). Ağ kavramı farklı alanlarda farklı temsiliyetlere sahip olmakla birlikte bu çalışmada sosyal bilimler açısından "ağ"ın ne anlama geldiği önem arz etmektedir. Sosyal bilimlerde bir ağ; "bireyleri, kurumları veya ülkeleri içeren birimler setidir ve birimlerin ne dereceye kadar, nasıl ve hangi açılardan birbirlerine bağlı olduğunu" tanımlamaktadır (Maoz, 2011: 7) ve ağ yapısı iki temel elemanı içermektedir. Bunlar; aktörler ve aktörler arasındaki ikili ilişkilerdir (Borgatti ve Halgin, 2011; Marin ve Wellman, 2014; Hanneman ve Riddle, 2005). Wasserman ve Faust (1994: 17) aktörleri "ayrık/münferit bireysel, kurumsal veya kolektif sosyal birimler" olarak tanımlamaktadırlar. Pryke'e göre (2012: 71) aktör, "sosyal varlığa verilen isim"dir. İlişki ise aktörler arasındaki bağa işaret etmektedir (Haythornthwaite, 1996). Bu temel formata bağı olarak çeşitli ağ türleri, değişen türlerdeki aktörler ve ilişkiler tarafından oluşturulabilir. Aktörlerin ve ilişkilerin türleri araştırmanın amacı ve odağına bağlı olarak seçilmektedir (Jo vd., 2016).

Bir ağ yapısı için büyüklük ilk göze çarpan özelliktir. Büyüklük sosyal yapıyı oluşturan aktörlerin sayısının bir fonksiyonudur. Bir ağda ne kadar çok aktör varsa o kadar çok potansiyel ilişki vardır. Bu anlamda bir ağda ilişkiler aktörlerin sayısına bağı olarak tanımlanır. Örgüt yapısında bağlantı sayısı arttıkça etkileşimin arttığını söylemek mümkün olur. Ancak bu yargı detaylı bir analiz için çok yüzeysel kalabilir. Bu bağlantıların ne kadarının gerçekten gerekli ne kadarının gereksiz (redundant) olduğu 
sorusu örgüt yapısının karakteri hakkında bilgi verecektir. Burt'un anlatımıyla (1995: 15-18) seyrek bilgi akışı sağlayan bir ağda bağlantılar arasında bir başka ilişki yoktur. Buna karşın yoğun bilgi akışında sıkı bir ilişki vardır. Bu durumda seyrek bağların olduğu ağdaki ilişkiler gereklidir. Çünkü ağ içindeki bilgi akışı tek tek her bir bağlantıya dayanmaktadır. Yoğun bağlantıya sahip ağlarda ise aynı bilgi farklı ilişkilerden sağlanabilir. Bu nedenle bağlantıların bir kısmı gereksizdir. Başka bir ifadeyle birinci tip bir ağ gereksiz bağların olduğu bir ağa göre daha verimlidir.

Ağları oluşturan aktörlerin aynı ilişkilere sahip olması durumunda yapısal denklik söz konusu olur (Burt, 2011). Örgütler gibi resmi yapılarda bu durum bağlantıların gereksizliğine de işaret eder. Aynı ortamları paylaşan insanların zamanla yapısal denklikleri söz konusu olur. Yapısal denk iki ağdan güçlü olan daha yararlıdır. Bir bağın güçlü olması temas sıklığı ile yakınlık boyutlarına bağlıdır (Burt, 2011). Örgütlerde bu yapıyı görebilmek birimler arasındaki ilişkilerin hem doğrudan hem de dolaylı bağlarının göz önünde bulundurulması ile mümkün olur. Bu halde örgütlerdeki birimlerin birbirleri ile ilişkileri güç, denklik ve gereklilik gibi bir kııım özelliklerin tanımlanmasına yardım edebilir. İlişkilerin nasıl tanımlanacağı bu noktada önem kazanmaktadır. von Tunzelman (2004) ilişkilerin oluşumunu üç grupta incelemiştir: fonksiyonel, kaynak ve coğrafya. Fonksiyonel ilişkilerde bağlantıların konusu örgütün fonksiyonlarıdır. Bağlar söz konusu fonksiyonlar üzerinde gelişmektedir. von Tunzelman'a (2004: 25) göre bu ağ yapısı örgütün merkezine yönetimi alarak temel ilişkileri tanımlar. Temel ilişkiler fonksiyonel olarak idare, üretim süreçleri, uygulama tekniği ve ürün bilgileri üzerine kuruludur. íkinci ağ ilişkilerini tanımlama şekli kaynaklardır. Kaynak ilişkilendirmelerinde örgütün faaliyetlerini yürütmesinde önem taşıyan kaynaklara yönelik bağlantılar ana unsurdur. Kaynaklar basit girdi-çıktı ilişkisi içinde tanımlanır. Buna göre örneğin yönetim için gerekli olan işgücü üniversitelerin endüstriye bir girdisi olarak düşünülür. İlişkileri kaynakların akışına göre tanımlamak örgütün içindeki fonksiyonlardan çok bu fonksiyonları ifade eden akışların dikkate alınmasını gerektirir. Üçüncü ilişkilendirme şekli coğrafyadır. Bu ilişki tanımlama şeklinde örgütün farklı coğrafyadaki ilişkileri tanımlanır. Coğrafik dağılım sektörel anlamda yerel, ulusal ve küresel olarak tanımlanabilir. Bu tanımda bölgelerin birbirleri arasında kesişim bölgeleri de vardır (von Tunzelman, 2004: 30).

Örgütlerin yapılarını ağ perspektifi ile incelemek için bu çalışmada iki varsayım kabul edilmiştir. Bunlardan ilki örgütlerin sosyo-teknik sistemler olduğu, ikincisi ise örgüt içindeki birimlerin sahip oldukları iş ilişkilerinin fonksiyonel ve etki temelinde tanımlandığıdır. Sosyo-teknik sistemlerde ilişkiler doğası nedeniyle gerekli ilişkilerdir (Trist, 1981; Geels, 2004; Baxter ve Sommerville, 2011). Bu nedenle örgütleri oluşturan birimlerin ilişkileri resmi yapılarını da yansıtma gücüne sahiptir. Sosyoteknik sistemlerin unsurlarının sosyal etkilere dayalı olarak etkileşimlerini inceleyen çalışmalar (Egghe, 2009; Linss ve Fried, 2010) genel olarak ilişkileri doğrudan ya da dolaylı ve aktif ya da pasif olmak üzere iki boyutta incelemişlerdir. Bu boyutlar çerçevesinde sistemin etkileşiminin birtakım göstergeler ile haritalandırıması mümkün olmaktadır. Örgüt bilim açısından bu göstergeler bir örgütün kurumsal yapısının dinamik karakterini tanımlar. Çalışmamızda kullanılan aşağıdaki temel göstergeler Linss ve Fried'ın (2010) bu kavramları ve hesaplama yöntemlerini ispatladıkları araştırmalarına dayandırılmıştır.

Bütünleşme. Birimin, sistemin bütünlüğüne katkı yapma derecesinin bir göstergesidir. Bütünleşme derecesinin yüksek olması birimin bütünlüğe olan katkısının yüksek olduğunu ve sistem içindeki diğer birimler ile ilişki kurabildiğini gösterir. Derecenin düşüklüğü birimin diğer birimlerden daha farklı olduğunu ve ilişki kuramadığını ifade eder. Bütünleşme kapasitesi birimler arasında birlikteliğin olması için gerekli en düşük etkili enformasyon oranıdır. Bu ölçüm bir sistemin alt kümelerini tanımlama olanağı sunar.

Harekete Geçiricilik (Şekillendiren/Nüfuz Eden). Harekete geçiricilik, bir birimin sistem içindeki diğer birimleri harekete geçirebilme etkisidir. Başka bir ifadeyle birimin şekillendirme gücünü ifade etmektedir. Bu özellikteki birimlerin aktif iletişim değerleri pasif iletişim değerlerinden daha yüksektir. Değerin yüksek olması diğer birimleri harekete geçirme açısından etkililiği ifade eder. Bu değerin yüksek olduğu birimler birtakım uygulamaların sistemin geneline sirayet etmesi açısından tercih edilir.

Harekete Geçicilik (Şekillenen/Etkilenen). Bir birimin diğer birimlerden etkilenme özelliğini ifade eder. Bu özellikteki birimlerin pasif iletişim değerleri yüksektir. Değer, uygulanan stratejilerin sonuçlarının izlenebilirliği açısından önemli ipuçları verir. Harekete geçicilik özelliği, birimlerin dolaylı pasif etkileri ile oluşmaktadır. Bu birimler, sistem içindeki dolaylı etkileşimlerden en fazla etkilenen birimlerdir. Sistem içindeki değişimlerden ilk etkilenen ve bu nedenle bu grup sistem içindeki dalgalanmaların ilk işaretlerini veren gruptur.

Sistem İstikrarı. Sistem istikrarı her tür dinamik sistemin kararlıığını ifade etmek için kullanılır. Burada tanımlanan kararlılık dinamik sistemin hareketinin öngörülen aralık ve büyüklük içinde, öngörülen şekilde gerçekleşmesidir. İstikrarlı sistemler öngörülebilir ve düzenli sonuçlar yaratır. İstikrarın belli bir değerin üzerinde gerçekleşmesi kurumsal katılığa neden olabilmektedir. Kurumsal katılık, birimlerin tepkilerinin değişimin karakterinden bağımsız olması anlamına gelmektedir. Bu durumda kurumsal bütünlük de zaman içinde tehlikeye girer. İstikrarın belli bir değerin altında olması ise dinamiklik anlamına gelir. Dinamik yapılar değişim konusuna duyarlı olabilen yapılardır. 
Kritiklik. Birimlerin kritikliği sistemin bir bütün olarak varlığı açısından önem derecesini ifade eder. Sistemin kritikliği ise sistemin değişime ne kadar hassas olduğu ile ilgilidir. Kritiklik derecesi en yüksek birim sistemin değişimi konusunda en etkili aktördür. Bu birimdeki bir değişim sistemin tümüne yönelik bir değişime neden olur.

Öngörülme. Öngörülme birim davranışındaki kararsızlığı ifade eder. Kararsızık derecesi yüksek birimlerin davranışlarını öngörmek göreceli olarak daha zordur. Birimlerin kararsızlığını belirleyen, çevresel yapıdan daha çok kendi içyapılarına yönelik dinamiklerdir. Kararsızlık derecesinin düşüklüğü birimlerin sistem dışı etkileşimlere ne kadar kapalı olduğunun göstergesidir. Aynı zamanda bu durum ilgili birimin dış etmenler tarafından iş birliğine açık olmadığını, bağımsız hareket edebildiğini göstermektedir. Kararsızık değeri yüksek birimler şeffaf ve paylaşımcı olmaları ve davranış değişimleri konusunda açıklayıcı tavır sergilemeleri durumunda sistem içinde değişimin başlangıç yeri olurlar.

\section{VERI VE METODOLOJI}

Ağ analizinin amacı aktörler arasında yer alan etkileşimlerin örüntülerini ve içeriklerini anlamaktır (Nelson, 2011). Bu nedenle ağ analizi aktörler arasındaki ilişkiler hakkındadır (Hanneman ve Riddle, 2005) ve aktörler arasındaki kaynakların değişimini ve aktörlerin kaynaklara erişimini araştıran bir yaklaşımdır (Haythornthwaite, 1996). Analize konu olan ağlar yönlendirilmiş/yönlendirilmemiş ve ağırlıklandırılmış/ağırlıklandırımamış olabilir. Yönlendirilmiş ağlar, bağların sadece bir yöne gittiği ağlardır. Örneğin iki ülke arasındaki ticareti temsil eden bir ağ yönlendirilmiştir (Wasserman ve Faust, 1994: 121122). Bağlarının herhangi bir yönünün olmadığı ağlar ise yönlendirilmemiş ağlardır. Bu tarz ağlarda A ile B aktörü arasında ne tür bir bağ var ise B ile A arasında da aynısı söz konusudur. Arkadaşlık ilişkileri veya akrabalık ilişkilerinden oluşan bir ağ buna örnek olarak verilebilir. Bununla birlikte her bir bağa bir sayı (ağılık) atandıysa o ağ, ağırıklı bir ağdır ve bu ağırlıklar; ilişkilerin yoğunluğunu, mesafesini veya maliyetlerini tasvir etmek için kullanılıyor olabilir (Hanneman ve Riddle, 2005: 13). Ağırlıklandırılmamış ağlarda ise bağlar ilişkinin yalnızca var olduğunu göstermektedir. Bu tür ağların ilişkiler matrisinde 1 ilişkinin varlığını ve 0 yokluğunu ifade eder.

Çalışmamızda Ankara'daki kamu kurumu niteliğindeki bir meslek örgütündeki birimlerin formal davranışları vaka çalışması yaklaşımı çerçevesinde ağ analizi ile ortaya konulmuştur. Bu çalışmada aktörler örgütteki birimlerdir ve evrak akışına dayanan bir ağı oluşturmaktadır (Şekil 1). Evrak ağı yönlendirilmiş ve ağırlıklandırıımıştır. Şekil 1'de birimler arasındaki çizgiler evrak ilişkilerini göstermekte ve evrak akışı arttıkça çizgiler kalınlaşmaktadır. 10 birimin incelendiği çalışmada 2016 yılına ait toplam 35.427 evrak akışı analiz edilmiştir.

\section{Şekil 1: Ağırıłılandırıımış Evrak Ağı}

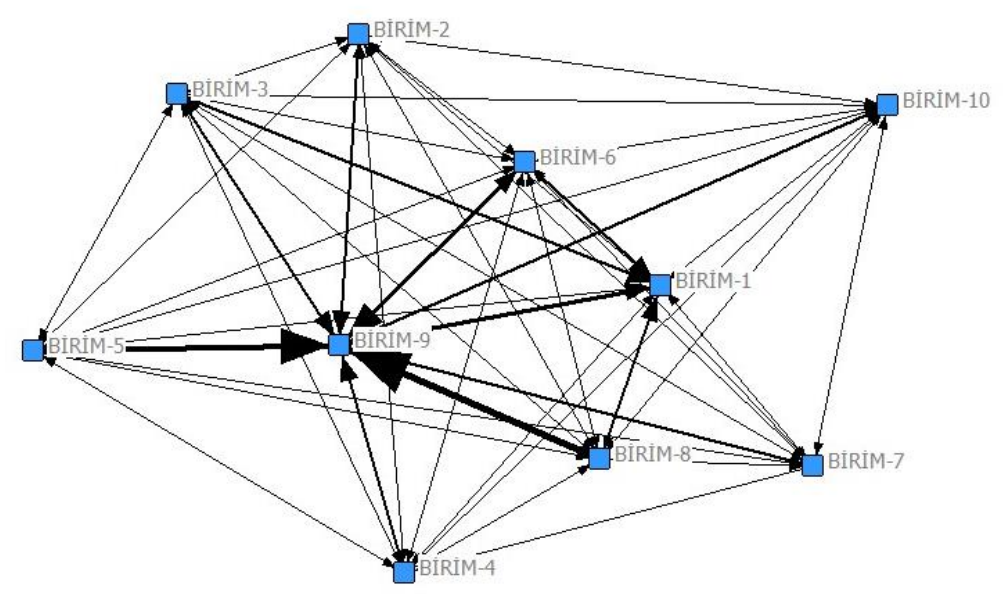

\section{BULGULAR VE TARTIŞMA}

Birimlerin davranışlarının ortaya çıkarılmasının hedeflendiği çalışmada ağ analizi ile altı temel gösterge hesaplanmıştır: bütünleşme, harekete geçiricilik, harekete geçicilik, istikrar, kritiklik ve öngörülme (Linss ve Fried, 2010). Birimlerin bu göstergeler açısından aldıkları değerler izleyen tablolarda sunulmuştur. 
Tablo 1: Bütünleşme Değerleri (\%)

\begin{tabular}{|l|l|l|l|l|l|l|l|l|l|}
\hline Birim 1 & Birim 2 & Birim 3 & Birim 4 & Birim 5 & Birim 6 & Birim 7 & Birim 8 & Birim 9 & Birim 10 \\
\hline 86,87 & 67,71 & 71,05 & 56,32 & 70,44 & 92,72 & 56,81 & 75,44 & 97,33 & 65,67 \\
\hline
\end{tabular}

Yapılan hesaplamalarda bütünleşme değerleri birimler açısından Tablo 1'de sunulmuştur. Bu durumda Birim 6 ve Birim 9'un genel bütünleşmeye katkısının en fazla olduğu görülmektedir. Bu durum, bu iki birimin sistemin genelinin bir arada olmasına en fazla katkı sağladığını göstermektedir. Bütünleşme değerinin yüksek olması Birim 6 ve 9'un diğer birimler üzerindeki nüfuzunun yüksek olduğu anlamına gelmektedir. Bu nedenle kültürel yapının gelişiminin ağırlıklı olarak bu iki birimin etkisi altında gelişeceği konusunda değerlendirmede bulunmak mümkündür. Birim 6 ve Birim 9'un çalışma dinamiği, kültürel yapısı ve iş görme geleneklerinin örgütün geneline diğer birimlere göre daha baskın olarak yaygınlaşacağı beklenmektedir.

Tablo 2: Harekete Geçiricilik Değerleri (\%)

\begin{tabular}{|l|l|l|l|l|l|l|l|l|l|}
\hline Birim 1 & Birim 2 & Birim 3 & Birim 4 & Birim 5 & Birim 6 & Birim 7 & Birim 8 & Birim 9 & Birim 10 \\
\hline 32,60 & 51,68 & 45,15 & 50,63 & 44,06 & 26,42 & 55,71 & 40,07 & 16,00 & 48,94 \\
\hline
\end{tabular}

Örgüt açısından harekete geçiricilik değerine ilişkin veriler Tablo 2 'de sunulmuştur. Bu tablo ışığında harekete geçiricilik değeri en yüksek olan aktörler Birim 2 ve Birim 7 olarak görülmektedir. Harekete geçiricilik etkisi yüksek olan Birim 2 ve Birim 7 diğer birimler üzerinde değişim ajanı (change agent) olarak etkide bulunma potansiyeline sahiptir. Bu iki birim örgütün değişim karakteri üzerinde söz sahibidir. Örgütsel değişim yapısının ağırlıklı olarak bu iki birimin tercihleri ve dinamikleri gölgesinde şekillenmesi beklenmelidir. Bu örgüt yapısında Birim 2 ve Birim 7'nin değişim ajanı olarak görev yapması durumunda daha hızlı ve etkili sonuca ulaşmak mümkün olabilecektir.

Tablo 3: Harekete Geçicilik Değerleri (\%)

\begin{tabular}{|l|l|l|l|l|l|l|l|l|l|}
\hline Birim 1 & Birim 2 & Birim 3 & Birim 4 & Birim 5 & Birim 6 & Birim 7 & Birim 8 & Birim 9 & Birim 10 \\
\hline 35,89 & 43,05 & 45,56 & 48,60 & 47,44 & 25,67 & 44,36 & 47,62 & 16,45 & 46,14 \\
\hline
\end{tabular}

Tablo 3 incelendiğinde harekete geçicilik değeri en yüksek olan aktörler sırasıyla Birim 4, Birim 5 ve Birim 10'dur. Bu bulgular ışığında kurumsal yapıya ilişkin değişimlerin öncelikle yukarıda belirtilen birimler üzerinden takip edilmesinin mümkün olduğu görülmektedir. Harekete geçicilik değeri en yüksek olan birim örgüt içindeki değişime en hassas olan birimi ifade etmektedir. Bu durumda Birim 4, Birim 5 ve Birim 10'un örgütsel değişim karşısında en hızlı tepki veren birimler olduğunu söylemek mümkündür. Örgütün çevresinde ya da içinde yaşanan değişimlerin en hızlı takip edilebileceği birimler de yine aynı birimlerdir. Bu birimler gösterge birimler olarak kullanılabilir ve böylece değişimlerin örgüt içindeki gelişimi izlenebilir.

Tablo 4: İstikrar Değerleri (\%)

\begin{tabular}{|l|l|l|l|l|l|l|l|l|l|l|}
\hline Birim 1 & Birim 2 & Birim 3 & Birim 4 & Birim 5 & Birim 6 & Birim 7 & Birim 8 & Birim 9 & Birim 10 & Sistem \\
\hline 30,25 & 74,94 & 62,88 & 95,07 & 65,03 & 15,97 & 100,00 & 58,13 & 5,95 & 75,04 & 56 \\
\hline Dinamik & Dinamik & Dinamik & Durağan & Dinamik & Dinamik & Durağan & Dinamik & Dinamik & Dinamik & \\
\hline
\end{tabular}

Ele alınan örgüt için istikrar değerleri ve bu değerler ışığında dinamik ve durağan yapıya sahip olan birimler Tablo 4'te sunulmaktadır. Sistem istikrarına en çok katkı yapan aktörler Birim 4 ve Birim 7'dir. Sistemin genel istikrarı \%56 olarak hesaplanmıştır. Bu sonuç sistemin ne atalet ne de çözülme/düzensizlik tehdidi altında olduğunu göstermektedir.

Tablo 5: Kritiklik Değerleri (\%)

\begin{tabular}{|l|l|l|l|l|l|l|l|l|l|}
\hline Birim 1 & Birim 2 & Birim 3 & Birim 4 & Birim 5 & Birim 6 & Birim 7 & Birim 8 & Birim 9 & Birim 10 \\
\hline 86,47 & 66,59 & 71,05 & 56,28 & 70,25 & 92,68 & 55,36 & 74,33 & 97,30 & 65,56 \\
\hline
\end{tabular}

Meslek örgütünde kritiklik değeri en yüksek olanlar Birim 6 ve Birim 9'dur (Tablo 5). Birimlerin değerlerinin (sırasıyla \%97,30 ve \%92,68) diğerlerinden oldukça yüksek olması örgüt içinde bu iki birimin kritiklik açısından farklı bir küme yarattığını göstermektedir. Bu durumda örgüt içindeki en etkili değişimlerin bu birimlerden başlayarak gerçekleştirilebileceği iddia edilebilir.

Tablo 6: Öngörülme Değerleri (\%)

\begin{tabular}{|l|l|l|l|l|l|l|l|l|l|}
\hline Birim 1 & Birim 2 & Birim 3 & Birim 4 & Birim 5 & Birim 6 & Birim 7 & Birim 8 & Birim 9 & Birim 10 \\
\hline 82,41 & 72,96 & 70,73 & 57,44 & 67,70 & 94,03 & 62,05 & 68,18 & 95,97 & 67,52 \\
\hline
\end{tabular}

Öngörülme göstergesine ilişkin değerler Tablo 6'da sunulmuştur. Buna göre Birim 6 ve Birim 9 en yüksek öngörülme değerine sahiptir ve kritiklik değerinde olduğu gibi bu iki birim ayrı bir grup oluşturmaktadır. Bu grubun davranışlarının izlenmesi ve bu davranışların nedenlerinin anlaşııması diğer birimlerle kıyaslandığına daha kolay olacaktır. Buna göre Birim 6 
ve Birim 9 daha çok kendi iç dinamiklerine dayalı olarak davranış sergileyen birimlerdir. Dışarıdan etkilerin birimlerin davranışlarını değiştirme gücü göreceli olarak daha kısıtlıdır.

\section{SONUÇ}

Bu çalışmada elde edilen sonuçlar sosyo-teknik sistemler açısından tanımlanan göstergelerin örgüt yapılarına uyarlanabileceğini göstermiştir. Çalışma, kaynağını sistem biliminde alan ve ağ perspektifinde yer alan kavramların kullanılması ile örgüt yapısını tanımlamayı hedeflemektedir. Bu açıdan bakıldığında çalışma örgütleri sosyo-teknik bir sistem olarak kabul ederek sistemi alt birimlerin birbirleri ile iletişim ve etkileşimleriyle analiz etmektedir. Böylece örgüt yapısını dinamik olarak ifade etme olanağı yaratımıştır. Örgüt yapılarının dinamik karakterde tanımlanması örgütün karakteristiğinde yaşanabilecek değişimler ile bu değişimlerin neden olacağı kapasite ve istikrar sorunlarını tanımlama imkânı sunmaktadır. Örgüt yapılarındaki dinamizm zaman ya da örgüt yapısını oluşturan bireylerde ya da görevlendirmelerde değişimler paralelinde gelişebilir. Böylece stratejik planlamadaki bir değişimin örgüt kapasitesi ve etkileşimi üzerinde ne gibi etkilerinin olabileceğini önceden simüle etmek mümkün olabilecektir.

Çalışma, örgüt yapısını oluşturan birimlerin birbirlerini etkileme gücü konusunda öngörülerde bulunma olanağı sunmaktadır. Böylece birimlerden birindeki değişimin (görev, personel ya da zaman gibi etkilerle olabilir) diğer birimler üzerinde ortaya çıkarabileceği etkileri takip edebilmek mümkün olacaktır. Böylece birimler arasındaki kaynak tahsisine dayalı kararların diğer birimler üzerindeki gerilimi önceden hesaplanabilecektir.

Çalışmanın bir diğer sonucu da burada geliştirilen yaklaşım ile birimlerde görev, personel ya da zaman gibi unsurlarda yaşanabilecek değişimlerin sistemin tamamı üzerindeki etkilerinin sistem istikrarı açısından analizinin mümkün olmasıdır. Böylece birimlerin sadece birbirlerini etkilemeleri değil aynı zamanda sistemin genelinde istikrar açısından yaratacakları etkinin de izlenmesi mümkün olacaktır. Bu sayede birimlerin örgütün geneli üzerinde yıkıcı etkilerde bulunma olasılığının da önüne geçilebilecektir.

Sonuç olarak çalışmada elde edilen bulgular ile örgüt bilimde bir sorun olarak görülen örgüt yapılarının örgüt davranışlarını dinamik yansıtamama sorununa bir çözüm geliştirilmiştir. Bu çözüm ile başta stratejik kararlara dayalı kurumsal tercihlerin örgüt yapısına nasıl yansıdığı, birimler arasındaki etkileşimi ne yönde şekillendirdiği ve birimler açısından verimli etkileşim ilişkilerinin nasıl kurulabileceği gibi pek çok soruya cevap üretme olanağı doğmuştur.

Çalışma zaman boyutunda bir yıllık dönemdeki etkileşimlere dayanmaktadır. Dönemin artırılması analizlerin derinliği açısından daha hassas değerlendirmelere imkân yaratabilecektir. Bu açıdan böyle bir analizin sürekli yapılması örgüt bilim içinde yapının sağlıklı bir şekilde takibi için bir gereksinimdir.

Çalışmada ilişkiler resmi ve formal ilişkiler olarak sınırlandırılmıştır. Bürokrasi kuramı çerçevesinde bu yaklaşımın nedenleri açık ve geçerli olsa da informal ilişkileri ele alan bir çalışmanın örgüt kültürleri arasındaki farklılıkları göstermesi açısından da öğretici olabileceği açıktır. Bu konuda gelecekte yapılacak çalışmaların yazına önemli katkı sağlayabileceği düşünülmektedir.

\section{KAYNAKLAR}

Bar-Yam, Y. (1997). Dynamics of complex systems. Reading, MA: Addison-Wesley.

Baxter, G., Sommerville, I. (2011). Socio-technical systems: from design methods to systems engineering. Interacting with Computers, 23(1), 4-17.

Borgatti, S. P., Halgin, D. S. (2011). On network theory. Organization Science, 22(5), 1168-1181.

Burt, S. R. (1995). Structural holes: the social structure of competition. USA: Harvard University Press.

Burt, S. R. (2011). Neighbor networks: competitive advantage local and personal. USA: Oxford University Press.

Egghe, L. (2009). Mathematical derivation of the impact factor distribution. Journal of Informetrics, 3(4), $290-295$.

Ercil, Y. (2014). Örgütsel tasarım ve değişim. (Ed) Ü. Sığrı, \& S. Gürbüz, Örgütsel davranış (ss. 634-659). İstanbul: Beta.

Geels, F. W. (2004). From sectoral systems of innovation to socio-technical systems: insights about dynamics and change from sociology and institutional theory. Research Policy, 33(6-7), 897-920.

Hanneman, R. A., Riddle, M. (2005). Introduction to social network. CA: University of California. http://faculty.ucr.edu/hanneman/nettex

Hanseth, O., Lyytinen, K. (2016). Design theory for dynamic complexity in information infrastructures: the case of building internet. (Ed) L. P. Willcocks, C. Sauer, \& M. C. Lacity, Enacting research methods in information systems (ss. 104-142). Cham: Palgrave Macmillan.

Haythornthwaite, C. (1996). Social network analysis: an approach and technique for the study of information exchange. Library and Information Science Research, 18(4), 323-342. 
James, L. R., Jones, A. P. (1976). Organizational structure: a review of structural dimensions and their relationships with individual attitudes and behavior. Organizational Behavior and Human Performance, 16, 74-113.

Jo, H., Park, Y., Kim, S. E., Lee, H. (2016). Exploring the intellectual structure of nanoscience and nanotechnology: journal citation network analysis. Journal of Nanoparticle Research, 18, 167

Lei, D., Slocum, J.W. (2005). Strategic and organizational requirements for competitive advantage. The Academy of Management Executive, 19(1), 31-45.

Linss V., Fried, A. (2010). The ADVIAN ${ }^{\circledR}$ classification - a new classification approach for the rating of impact factors. Technological Forecasting \& Social Change, 77, 110-119.

Maoz, Z. (2011). Network of nations. The evolution, structure, and impact of international network, 1861-2001. USA: Cambridge University Press.

Marin, A., Wellman, B. (2014). Social network analysis: an introduction. (Ed) J. Scott, and P. J. Carrington, The SAGE handbook of social network analysis (ss. 11-25). Great Britain: SAGE.

McKelvey, B. (1999). Complexity theory in organization science: seizing the promise or becoming a fad?. Emergence, 1(1), 5-32.

Nelson, R. E. (2011). The strength of strong ties: social networks and intergroup conflict in organizations. (Ed) M. Kilduff and A. V. Shipilov, Organizational network volume II (ss. 3-26). London: SAGE.

Pryke, S. (2012). Social network analysis in construction. Chichester: John Wiley and Sons.

Read, G. J., Salmon, P. M., Lenné, M. G., Stanton, N. A. (2015). Designing sociotechnical systems with cognitive work analysis: putting theory back into practice. Ergonomics, 58(5), 822-851.

Rosenthal, C. (2013). Big data in the age of the telegraph. McKinsey Quarterly, 1.

Rousseau, D. M. (1977). Technological differences in job characteristics, employee satisfaction, and motivation: a synthesis of job design research and sociotechnical systems theory, Organizational Behavior and Human Performance, 19(1), 18-42.

Stacey, R. D. (1995). The science of complexity: an alternative perspective for strategic change processes. Strategic Management Journal, 16(6), 477-495.

Trist, E. (1981). The evolution of socio-technical systems. Occasional Paper, No.2.

Von Tunzelmann, N. (2004). Network alignment in the catching-up economies of Europe. (Ed) McGowan F., Slavo R., \& von Tunzelmann N., The emerging industrial structure of the wider Europe (ss. 24-40). Routledge.

Wasserman, S., Faust, K. (1994). Social network analysis: method and applications. Cambridge: Cambridge University Press.

Wheatley, M. (2006). Leadership and the new science. Berrett-Koehler Pub., 27-32. 